\title{
Narrativas de vida e fios que atravessam a docência: compondo tramas de uma professora arquiteta
}

\author{
Narratives of life and threads that cross teaching: composing the plots of an \\ architect professor
}

Julia Bolssoni Dolwitsch ${ }^{1 *}$, Helenise Sangoi Antunes ${ }^{2}$

\begin{abstract}
RESUMO
O artigo objetiva compreender os percursos formativos de uma professora arquiteta que assumiu a docência como atividade profissional. $\mathrm{O}$ estudo buscou apoio metodológico na pesquisa (auto)biográfica, utilizando como metodologia a investigação biográficonarrativa e fazendo uso de entrevistas narrativas e diário de campo como instrumentos de pesquisa. O processo de análise foi pautado pela análise narrativa e produziu dois "movimentos": o primeiro envolveu a reconstrução das trajetórias de vida como textos narrativos, compondo tramas; o segundo fez surgir a "imagem" do "tear biográfico", um dispositivo que impulsionou o entrelaçamento das tramas, possibilitando a composição de tecituras que constroem a docência dos participantes da pesquisa. Neste artigo foi enfatizada a análise produzida no primeiro movimento, reconstruindo a trajetória de vida de uma professora arquiteta. Foi possível compreender que a composição das tramas dessa professora revelou que a construção docência não tem uma definição exata, sendo construída nos percursos de vida, nos modos de escritas de si e no entrelaçamento com outras tramas, outras histórias, outras memórias. Tramas que revelaram que a docência acontece em um processo permanente de (auto)formação e (auto)conhecimento.
\end{abstract}

Palavras-chave: Formação de Professores. Pesquisa (Auto)biográfica. Análise Narrativa.

\section{ABSTRACT}

The article aims to understand the training courses of an architect professor who assumed teaching as a professional activity. The study sought methodological support in (auto) biographical research, using biographical-narrative research as methodology and making use of narrative interviews and field diaries as instruments for the production of information. The analysis process was guided by narrative analysis and produced two

\footnotetext{
${ }^{1}$ Colégio Militar de Santa Maria (CMSM)

*E-mail: professorajulia2014@gmail.com

${ }^{2}$ Universidade Federal de Santa Maria
} 
"movements": the first involved the reconstruction of life trajectories as narrative texts, composing plots; the second gave rise to the "image" of the "biographical loom", a device that boosted the interweaving of the plots, enabling the composition of weavings that build the teaching of the research participants. In this article, the analysis produced in the first movement was emphasized, reconstructing the life trajectory of an architect professor. It was possible to understand that the composition of the plots of this teacher revealed that the construction of teaching does not have an exact definition, being built in the life paths, in the ways of writing itself and in the intertwining with other plots, other stories, other memories. Plots that revealed that teaching takes place in a permanent process of (self) formation and (self) knowledge.

Keywords: Teacher Education. (Auto) biographical research. Narrative Analysis

\section{INTRODUÇÃO}

No processo de construção da narrativa, aquele que narra o seu percurso de vida tem a possibilidade de "revelar o sentido da sua vida", de refletir sobre sua própria trajetória, de eleger os acontecimentos que foram significativos na sua história e de buscar a compreensão de si mesmo, mergulhando em um processo de (auto)conhecimento. Como tão bem nos esclarece Abrahão (2006), é nesse ponto que a narrativa é compreendida como processo formativo de ressignificação do vivido, um processo em que o narrador tem a possibilidade de retomar a sua história e atribuir novos sentidos e significados às suas trajetórias.

Narrativas memorialísticas não obrigatoriamente guardam verdades, mas representações sobre o que se viveu, "restando esta tensão entre o que aconteceu e o que o sujeito desejaria que tivesse acontecido, ou como ele concebe hoje o acontecido" (p. 21-22). As lembranças estão relacionadas aos significados que cada narrador atribui às suas reminiscências. Assim, é "importante considerarmos o que foi lembrado, porque o que foi lembrado é o que hoje recebe algum sentido" (FISCHER, 2011, p. 22).

Diante do exposto, é importante ressaltar que as narrativas privilegiam a realidade do que é experienciado pelo narrador, elas não são cópias da realidade, mas propõem representações e interpretações particulares do mundo dentro de um contexto sóciohistórico. Desta forma, as narrativas não estão abertas à comprovação, não podem ser julgadas como verdadeiras ou falsas, visto que "elas expressam a verdade de um ponto de vista, de uma situação específica no tempo e no espaço" (JOVCHELOVITCH e BAUER, 
2011, p. 110).

Na compreensão de Abrahão (2004), reconhecer a reconstrutividade da memória como percepção pessoal do que foi vivido, não elimina o papel do pesquisador na interpretação das narrativas. O investigador precisa fazer uma leitura com base em uma "referência de verdade", respeitando aquilo que o narrador estabeleceu como verdadeiro. Além disso, precisa compreender o objeto de estudo em duas perspectivas: "na perspectiva pessoal/social do narrador - que representa as individualidades e na perspectiva da dimensão contextual da qual essas individualidades são produtos/produtoras" (p. 221).

Assim, considerando o caráter singular e ao mesmo tempo contextual das trajetórias de vida e com o objetivo de fazer um recorte no que foi proposto na pesquisa de doutorado ${ }^{3}$, buscamos compreender, por meio da pesquisa (auto)biográfica, os percursos que levaram uma bacharela em Arquitetura e Urbanismo a assumir a docência como atividade profissional.

$\mathrm{Na}$ sessão que segue, delinearemos o percurso metodológico empreendido na investigação, enfatizando os movimentos produzidos para a análise das informações que emergiram da pesquisa. Em uma terceira sessão, procederemos com a apresentação da trajetória de vida da professora arquiteta, com a proposta de compreender os seus percursos de vida e de formação até chegar a constituição da sua docência. Finalizamos a nossa reflexão com a escrita de algumas considerações finais.

\section{PERCURSOS METODOLÓGICOS}

O giro narrativo, hermenêutico e interpretativo presente nas ciências humanas e sociaistem possibilitado $\mathrm{m}$ odos próprios de procedimentos metodológicos dentro da abordagem (auto)biográfica, principalmente porque permite representar um conjunto de dimensões da experiência vivida que a investigação habitual muitas vezes não valoriza (BOLÍVAR, 2014). Desta forma, para compreender as trajetórias de vida e os processos formativos de construção da docência da professora envolvida no estudo, optamos pelo método (auto)biográfico por meio da investigação biográfico-narrativa.

O enfoque biográfico-narrativo, conforme estudos de Bolívar e Domingo (2006),

3 O texto é oriundo da pesquisa de doutorado realizada no período de 2014 a 2018, no Programa de PósGraduação em Educação da Universidade Federal de Santa Maria. 
tem a pretensão de explorar os significados profundos das histórias de vida. Diante disso, não fica limitado a uma metodologia de recolha e análise dos dados, mas sim constitui-se dentro de uma perspectiva própria, como um processo investigativo que possibilita a construção do conhecimento nas pesquisas educacionais e sociais.

Para os autores esse enfoque pode ser caracterizado por cinco princípios básicos: narrativo - em que as percepções e os conhecimentos construídos ao longo da vida dificilmente são percebidos e transmitidos de outra forma que não seja pela narrativa; construtivista - permitindo que a história de vida seja compreendida como um processo constante de (re)significação, reconstrução, reflexão, assimilação e superação; contextual - possibilitando entender que as narrativas biográficas apenas terão sentido quando forem produzidas dentro dos contextos sociais, culturais, políticos que as constituem; interacionista - implica pensar que as biografias adquirem e alteram sentidos à medida que interagem com outras vidas, histórias, contextos, acontecimentos, situações, e se constituem por meio da própria reorganização da narrativa; e dinâmico - em que a narrativa faz parte de movimento contínuo de construção e reconstrução dentro de um componente temporal.

O marco biográfico, considerando suas implicações metodológicas e epistemológicas no processo de formação de adultos, tem como foco as investigações com fontes pessoais e busca documentar, a partir de experiências, acontecimentos e situações sociais, trajetórias de vida e de formação e questões identitárias. Segundo os autores, nesse marco estão inseridos

(...) todos los enfoques y vías de investigación cuya principal fuente de datos se extrae de biografías, material personal o fuentes orales, que dan sentido, explican o contestan preguntas vitales actuales, pasadas o futuras, a partir de las elaboraciones o posibles argumentos con los que se cuentan experiencias de vida o historias vividas desde la perspectiva de quien las narra (BOLÍVAR e DOMINGO, 2006, p. 4)4.

4 (...) todas as abordagens e canais de pesquisa cuja principal fonte de dados e extraída de biografias, material pessoal ou fontes orais, que dão significado, explicam ou respondem questões vitais, passadas ou futuras, por meio das elaborações ou possíveis argumentos com os quais se contam experiências de vida ou historias vividas a partir da perspectiva de quem as narra (BOLÍVAR e DOMINGO, 2006, p. 4, tradução minha). 
Assim, por meio dessa metodologia, o pesquisador não pode apenas estar preocupado em descrever ou verificar situações, mas sim em privilegiar os relatos de vida dos sujeitos envolvidos e com eles a dimensão emotiva da experiência, a complexidade das relações e das singularidades presentes em cada ação, considerando os fatores que influenciam as atitudes ao longo da vida (BOLÍVAR e DOMINGO, 2006).

Cabe mencionar que os participantes da investigação maior, mencionada anteriormente, foram professores bacharéis egressos do $\mathrm{PEG}^{5}$ e foram selecionados considerando alguns aspectos, a saber: professores bacharéis que ingressaram no PEG no primeiro semestre de 2016; que atuam/atuaram ${ }^{6}$ na docência no contexto da Educação Profissional e Tecnológica e/ou do Ensino Superior; que atuam/atuaram 1 (um) ano ou mais como docentes. A partir de um levantamento realizado por meio da aplicação de um formulário digital, recebemos o retorno e a disponibilidade de participação no estudo de quatro (04) docentes: Professora P, com experiência de 17 anos no Ensino Superior; Professor G, com experiência de dois (02) anos na Educação Profissional Técnica de Nível Médio; Professor S, com experiência de dois anos na Educação Profissional e Tecnológica, atuando nos Cursos Superiores e Técnicos; e Professor B, com experiência de três (03) anos no Ensino Superior e quatro (04) anos na Educação Profissional e Tecnológica, atuando nos Cursos Superiores e Técnicos. Neste artigo optamos por fazer um recorte na pesquisa e dar visibilidade para a trajetória de vida da professora $\mathrm{P}$, por compreender que a sua trama narrativa marca importantes diálogos para a área de formação de professores. Optamos por manter o anonimato dos professores envolvidos no estudo, definindo, por meio de contrato narrativo, que utilizaríamos a letra inicial dos nomes para referi-los.

Para a construção das tramas, utilizamos como instrumentos de coleta entrevistas narrativas organizadas a partir de tópicos guia (BAUER; GASKELL, 2011), com tópicos que guiaram a entrevista possibilitando que os participantes trouxessem à tona suas histórias com maior liberdade, a partir de pontos mais específicos da investigação. Além

5 O PEG, na modalidade presencial, possibilita uma formação pedagógica para os profissionais portadores de diploma de graduação (bacharéis ou tecnólogos) que atuam, ou pretendem atuar, como professores na Educação Profissional, principalmente Técnica de Nível Médio. Foi criado em 2009 e é uma proposta articulada entre os Centros de Ensino da UFSM - Centro de Educação (CE), Centro de Ciências Rurais (CCR), Colégio Técnico Industrial (CTISM) e Colégio Politécnico da UFSM.

6 Utilizamos a expressão atuam/atuaram, porque, no contexto da pesquisa, dois participantes ocupavam cargos provisórios (como professores substitutos) no momento da coleta de informações. 
das entrevistas, utilizamos como instrumento metodológico o Diário de Campo, com o intuito de descrever como as entrevistas foram acontecendo e registrar as linguagens não verbais que apareceram no diálogo com os participantes.

Após a realização das entrevistas realizamos a transcrição das informações e a elaboração dos quadros sínteses, com base nas orientações teóricas propostas por Bolívar, Domingo e Fernández (2001). A construção dos quadros não teve a intenção de organizar os dados de acordo com um conjunto específico de categorias comuns, mas auxiliar a organização temporal e temática para a construção das trajetórias individuais, conferindo importância e valorizando as experiências implicadas nas histórias de vida de cada professor participante desta pesquisa. Assim organizamos a análise a partir de dois movimentos.

O primeiro movimento envolveu a reconstrução das trajetórias de vida como textos narrativos, compondo tramas. Essas trajetórias foram reconstruídas com o auxílio do quadro síntese, a partir de alguns "fios biográficos" que conduziram a análise: "percursos formativos" (gênese, lembranças de infância, adolescência e vida adulta, percurso formativo acadêmico); "percursos profissionais" (experiências profissionais e acontecimentos que antecederam a docência); e "percursos na/da docência" (inserção na docência, exigências e desafios, aprendizagens, momentos marcantes, experiências de aula, organização e planejamento das aulas, contribuições do PEG, compreensão sobre o ser professor) ${ }^{7}$.

Para compreender a construção da docência de bacharéis egressos do PEG, empreendemos ainda um segundo movimento, fazendo analogia ao tear - artefato ou máquina que permite que os fios se entrelacem para compor o tecido. Mas não um tear qualquer, nesta pesquisa fazemos referência ao "tear biográfico" que são as próprias narrativas de vida repletas de sentidos e significados, que, ao serem rememoradas, produziram movimentos (similares aos do tear) e [re]significações. "Tear biográfico" como um dispositivo que impulsionou, no contexto desta investigação, o entrelaçamento de tramas que carregam marcas pessoas, culturais, históricas e sociais, possibilitando a composição de tecituras - representações, sentidos e saberes - que constroem a docência de bacharéis egressos do PEG.

7 É importante destacar que neste artigo daremos maior visibilidade à análise empreendida a partir do primeiro movimento, com destaque para a trajetória da professora $\mathrm{P}$ (professora arquiteta). 
Cabe destacar que o entrelaçamento das tramas não aconteceu por meio de instrumentos de categorização de dados, mas foi realizado pelas pesquisadoras, à medida que fomos construindo as trajetórias individuais. Foi como construir os tecidos por meio do tear, a partir dos "fios biográficos" elaboramos as tramas, a partir das tramas fomos entrelaçando, fomos percebendo como cada participante, nos seus percursos de vida, constrói à docência. Até chegar na composição das tecituras - das representações, dos sentidos e dos saberes que marcam, de certa forma, o modo de ser e constituir-se professor.

Conforme destaca Cusati, Santos e Cusati (2021, p. 336) "são muitos elementos que compõem a atividade docente e quando é utilizada a pesquisa qualitativa para investigar processos constantes ao longo da vida de sujeitos" - quando conseguimos ter acesso a densidade de tecituras que compõem as historias - não podemos ignorar os símbolos presentes na especificidade de cada cultura.

Assim, o resultado não foi um informe objetivo e neutro, nem mesmo uma simples transcrição de dados, consistiu em construir, a partir de uma análise narrativa bastante densa, uma trama, um enredo, para atribuir sentido às informações narradas, considerando os diferentes contextos, cenários, rupturas; diferentes formas de representar e manifestar a vida que foi contada.

\section{Narrativas... “(...) Eu não estou pronta, ninguém vai estar pronto (...) Eu sou um processo em continuação..."}

A professora arquiteta tem 49 anos, é casada e tem três filhos (duas meninas e um menino). É bacharel em Arquitetura e Urbanismo pela Universidade Federal de Pelotas (UFPel). Tem Especialização em Interpretação de Imagens Orbitais e Suborbitais, Mestrado em Geomática e Mestrado em Engenharia Agrícola, todos pela UFSM. É doutoranda do Programa de Pós-Graduação em Geografia do Centro de Ciências Naturais e Exatas (CCNE) da UFSM; arquiteta concursada da Prefeitura Municipal de Santa Maria/RS e professora, desde 2006, do Curso de Arquitetura e Urbanismo, da Universidade Luterana do Brasil (ULBRA) na cidade de Santa Maria/RS. Sua experiência como docente no Ensino Superior vem sendo construída desde 2001.

A entrevista com a professora foi a segunda a ser realizada e aconteceu na tarde do dia 16 de setembro de 2016, na sala 3377 do Centro de Educação da UFSM. Antes de 
iniciarmos a entrevista conversamos um pouco, de maneira informal, em um clima muito agradável. Falamos de nós, das nossas vidas e das nossas escolhas. Das escolhas que vão sendo delineadas conforme caminhamos, conforme vamos optando por aquilo que é mais importante para a nossa felicidade. Após esse primeiro momento de conversa, iniciamos a entrevista, retomamos o pedido para gravar a sua fala e apresentamos novamente os primeiros tópicos do roteiro (gênese, lembranças significativas da escola, percurso formativo acadêmico, experiências e marcas na trajetória que antecedem o ingresso na docência). A primeira entrevista teve duração de aproximadamente uma hora e quinze minutos.

A segunda entrevista foi realizada na tarde do dia 25 de julho de 2017, na sala 3332A do Centro de Educação. Nesse reencontro, conversamos sobre os desafios de conciliar a vida com as atividades cotidianas: da docência, do doutorado, do trabalho na prefeitura, da casa, dos filhos, enfim, atividades que são frutos das nossas próprias escolhas. Após essa conversa inicial, anunciamos a segunda parte do roteiro, que envolvia falar sobre os seus percursos na/da docência.

Ao longo das entrevistas com a professora não foi preciso fazer muitas interferências, suas narrativas fluíram tranquilamente e, conforme contava a sua história, os tópicos do roteiro iam sendo contemplados. Percebemos que ela estava bastante à vontade, era como se estivéssemos em uma roda de amigos falando sobre a vida. Nossas interferências foram no sentido de que ela pudesse falar um pouco mais sobre os vínculos construídos no PEG.

A sensibilidade com que a professora fala da sua vida foi registrada em diferentes momentos ao longo dos seus relatos - pelo olhar, pelo tom da voz, pelo sorriso que esteve sempre presente, até mesmo nos momentos mais difíceis - nas lembranças que a fizeram chorar.

A professora inicia a sua história falando sobre a sua origem e aqui já surge “(...) uma das minhas barreiras, falar da gênese" (p. 1). Nasceu nos Estados Unidos em 9 de junho de 1969 e veio para o Brasil ainda pequena, “(...) com seis pra sete anos. Por que que eu nasci lá?" (p. 1) Porque o seu pai estava fazendo doutorado ou pós-doutorado, não conseguiu lembrar com clareza no momento do relato. Repleta de orgulho, fala dos pais com um carinho muito especial:

Os meus pais sabiam português e inglês, eles eram daqui né, quer dizer, o pai era espanhol, mas ele veio pequeno para o Brasil e se naturalizou 
brasileiro, aí depois que ele foi fazer os estudos. Ele fez Agronomia no Rio de Janeiro e a mãe iniciou Odontologia e depois fez Ciências Domésticas. É engraçado que aqui ela foi professora das escolas rurais também, ela foi das brizoletas - é brizoletas que chama né? - e eles se encontraram em um congresso, que era da agronomia e as escolas rurais também tinham a mesma questão mais sociológica e filosófica (p. 2).

O que são Brizoletas? São conhecidas como escolinhas do Brizola, fruto do projeto "Nenhuma criança sem escola no Rio Grande do Sul”, criado por Leonel de Moura Brizola em 1946 e implementadas a partir de 1959 (QUADROS, 2005). Apesar de todas as dificuldades enfrentadas na época, a "Brizoleta é um reflexo de um pensamento, no qual se pode melhorar a sociedade por meio da educação. (...) podendo ser entendida como símbolo de uma época de mudanças através da educação" (MORAES e MARINHO, 2017, p. 617). Uma educação que, para Freire (1987), pode construir sujeitos críticos, que se posicionem perante a sociedade e que lutem por um espaço mais igualitário e contextualizado. Talvez a implicação social que aparece de forma tão presente ao longo das narrativas da professora, possa estar entrelaçada, de alguma forma, às heranças culturais deixadas pela mãe.

Em relação à trajetória nos Estados Unidos, traz algumas lembranças escolares (da Educação Infantil). Lembranças que carregam marcas e traduzem a sua forma de ser: alguém crítica, criativa e ética, que, antes de tomar qualquer decisão ou se expor, gosta muito de observar e analisar as situações. Alguém que tem o seu próprio tempo para aprender, que gosta das artes e de tudo aquilo que não seja mecânico, engessado e sem movimento. Conforme Josso (2010), a narrativa permite movimentos de consciência de fatos e vivências do passado que marcaram a nossa trajetória, possibilitando definir alguns desafios no presente. Para a professora o grande desafio, na construção da sua docência (construção permanente como se refere), é “(...) entender que cada aluno é um, mas esse um, tem que ser um com a sua identidade, com a sua cultura, com o seu contexto" (p. 9), com o seu próprio ritmo para aprender. Portanto, sempre reconheceu isso na sua prática e acredita que esse olhar individual e atento faz toda a diferença no processo de aprendizagem do aluno.

O seu retorno ao Brasil aconteceu no ano de 1975, em função de um convite recebido pelo pai para atuar como professor visitante na cidade de Viçosa, em Minas 
Gerais. "Então quando eu saio de lá, semialfabetizada, eu venho pro Brasil e tenho um choque muito forte. A gente veio dos Estados Unidos, onde as escolas eram grandes, eram turnos integrais, e aí a gente vem pro interior de Minas Gerais" (p. 1). Contexto de “(...) terra crua, um certo preconceito nosso como criança, com outra cultura, a gente não se adaptou” (p. 1). Como sabiam que ficariam em Viçosa apenas um certo período, as aulas começaram a ser ministradas pela sua mãe, em casa. Não é difícil perceber na fala e no olhar da professora a paixão com que se refere a própria família, traduzida, neste momento da sua trajetória, pela dedicação da sua mãe.

Quando minha mãe me deu aula, o que mais me marcou foi a atenção e a paciência, que não se tem hoje na escola. Até hoje me lembro da disciplina do horário para as tarefas e do jeito que ela me instigava a resolver as questões propostas. Quando fecho os olhos, me lembro do livro com formas diversas de encaixar (p. 1).

Logo depois o seu pai foi convidado para trabalhar em Pelotas/RS e depois convidado para trabalhar aqui, na Universidade Federal de Santa Maria. Continuando a falar do seu percurso escolar, relata que, naquela época, era raro alguém vir do exterior, o intercâmbio não era algo tão comum como nos dias atuais, então "ser" do exterior era uma novidade na escola e para a professora algo muito ruim. Por que?

\footnotetext{
Porque na infância (na escola) eu sempre era como um bichinho de estimação, assim, raro. Vinham conversar comigo só por causa disso. E eu sempre tive essa questão de quem é amigo de fato. Aí eu via que era só interesse, ou pra ser amigo do grupo. A se tu conversou com a $P$ então agora tu mudou de status, que isso né?! Então era muito ruim, muito ruim, além da questão da alfabetização que eu não sabia. Aí eu comecei a perder um pouco do pouco vocabulário que eu tinha, porque eu não era alfabetizada ainda, e também não tinha o vocabulário português. Então eu me senti assim perdida nesse momento inicial chorava porque eu não sabia falar inglês e não sabia falar português, o que eu falava ninguém me entendia (risos) (p. 2, grifos meus).
}

Certamente foram acontecimentos que marcaram profundamente a sua trajetória, principalmente por ser alguém que compreende o valor das amizades, da ética e do 
respeito incondicional entre os seres humanos. Alguém que, como professora, valoriza a afetividade, o diálogo e a amorosidade no processo de ensinar e aprender com os alunos. Apesar de ter "cara fechada (...) o pessoal sempre me chama de mãezona" (p. 9). Isto nos lembra o que escreve Freire (2018, p. 162-163), “O diálogo entre professoras ou professores e alunos ou alunas não os torna iguais, mas marca a posição democrática entre eles ou elas". Implica um respeito fundamental entre os sujeitos que estão engajados neste processo e revela uma relação que não anula, como as vezes se pensa, a possibilidade de ensinar. "Pelo contrário, ela funda esse ato, que se completa e se sela no outro, o de aprender".

Para Delory-Momberger (2008, p. 113), a escola representa, para cada geração, diferentes experiências ao longo de determinados períodos da vida, seja na infância, na adolescência e, para alguns, na fase adulta. “(...) enquanto primeiro espaço de socialização secundária, a escola representa um dos principais testes do mundo social e cultural de origem e do sistema de representações do qual esse indivíduo é portador". Viver no tempo e no espaço da escola a conexão das formações física, psíquica, intelectual, relacional e social, "faz da escola um cadinho de experiências na construção da biografia pessoal e das representações que a acompanham". Na vida da professora arquiteta, representações que ainda marcam e definem algumas barreiras no seu modo de ser: “(...) normalmente quando alguém me pergunta: da onde tu é? Eu respondo: a daqui, eu vou enrolando pra não responder a pergunta" (p. 2). Assim, a escola está no centro das representações que compõem as experiências subjetivas dos alunos.

Dos professores que marcaram a sua trajetória, lembra com carinho o professor de geografia do Ensino Fundamental:

Ele foi o primeiro professor crítico, que me fez ser um pouco crítica no conhecimento, (...) crítica de tentar analisar as coisas e o $R$ foi $o$ primeiro da Geografia crítica a conseguir. Foi o meu diferencial pra passar no vestibular, eu gabaritei a geografia que foi uma das piores provas na época (p. 2).

Dos tempos vividos no Ensino Médio em uma escola pública, relata sobre o privilégio de ter sido aluna de excelentes professores - "eram professores tanto do Estado, como dos cursinhos" (p. 2) - registrando que a formação e o conhecimento adquiridos com eles foram plenos, relevantes e fundamentais para a sua aprovação e 
ingresso no Ensino Superior: "consegui passar na primeira turma na Universidade Federal de Pelotas (UFPel)" (p. 3).

“Por que UFPel e por que Arquitetura e Urbanismo?" (p. 3). Porque ela queria independência e autonomia, queria ser reconhecida pelas suas lutas e suas conquistas. "Na verdade por ser filha do professor Gustavo ${ }^{8}$ e da amiga Tanira - que sempre foi muito bem quista nas suas relações de amizade, eu queria autonomia, então a minha escolha não foi por profissão, mesmo sabendo a tendência" (p. 3). Revela, ao longo do seu relato, que nunca nasceu com aquela ansiedade de saber o que escolher como profissão, mas compartilha alguns desejos: primeiro - “(...) não sei se porque era americana sempre quis ser Astronauta", mas naquela época mulher não podia e quando começaram a admitir mulheres, a professora não tinha mais idade. Segundo - Piloto de Aeronaves - “(...) quando abriu concurso pra aeronáutica os meus olhos brilharam, mas não me aceitaram porque eu já estava com uns trinta e cinco anos, então não deu pra ser dessa área". Depois pensou em ser Médica Veterinária - pois gostava de animais e se aproximava muito das áreas naturais, mas como "autodefesa" não quis fazer veterinária, porque sabia que iria sofrer caso não conseguisse ajudar algum animal. Quarto - Policial, “(...) porque sempre quis defender os outros”. De Policial a bacharel em Direito, “(...) cheguei a pensar, na parte criminalista. Mas nada assim certo, ao contrário do meu irmão mais velho que sempre pensou em odontologia" (p. 3, grifos meus).

Ao rememorar os fatos da vida, reflete sobre a importância de alguns pressupostos para a própria realização como pessoa e profissional, quando diz: “(...) eu queria ser conhecida como P, por quem eu sou, queria a minha independência como mulher" (p. 34). Nesta direção, procurou analisar quais cursos não tinham em Santa Maria e quais tinham algum vínculo com as artes e com a matemática - áreas com as quais tinha maior afinidade. A partir disso, ingressou, em 1987, no Curso de Arquitetura e Urbanismo da UFPel e conseguiu a tão desejada independência - “(...) poder pensar sozinha, poder refletir, se organizar" (p. 4). Quando lemos as narrativas da professora, percebemos o quanto o percurso acadêmico foi importante em sua vida, pois representou “(...) uma experiência muito rica tanto de formação quanto de contextualização" e, principalmente, de reconhecimento - “(...) eu consigo ser reconhecida, que é o que eu buscava né. (...) lá eu consigo achar que o meu estudo era significativo, com os meus colegas me avaliando,

8 Foi professor do Curso de Agronomia da Universidade Federal de Santa Maria (UFSM). 
sem conhecer o que eu era antes". Suas narrativas conduzem-nos ao que escreve DeloryMomberger (2008), quando se refere à construção do projeto que o sujeito faz de si mesmo. Não como algo consciente, mas como “(...) uma orientação para o futuro” (p. 63), pois não paramos de prever nossas atividades, nossos compromissos e projetos.

\begin{abstract}
Nessas construções projetivas, o pensamento e o olhar dos outros desempenham um papel de espelho (...). Construo-me, assim, na projeção do olhar do outro, na antecipação da leitura do outro. De certo modo, não paro de me escrever, isto é, de compor os efeitos de escrita que vêm, ao mesmo tempo, modelar e autenticar meu estilo, permitindo reconhecer-me a mim mesmo e ser reconhecido pelos outros (DELORY-MOMBERGER, 2008, p. 65, grifos da autora).
\end{abstract}

Neste sentido, a construção biográfica, por meio das narrativas, está registrada numa dinâmica temporal que articula passado, presente e futuro, na qual a projeção do "por-vir", do movimento de vir a ser, exerce um "papel motriz", ou seja, uma força que impulsiona e "permite fazer acontecer a fábula de uma história que desenha um futuro possível e se concretiza em projetos singulares (DELORY-MOMBERGER, 2008, p. 65, grifos da autora)". Assim, a "história de vida" não é propriamente a história da vida como aconteceu, não podemos esquecer que "a vida narrada não é a vida" (Ibidem, p. 96), mas representações, construções narrativas que o sujeito elabora quando é convidado a “contar” sua vida. “(...) a ficção apropriada pela qual o sujeito se produz como projeto dele mesmo" (DELORY-MOMBERGER, 2008, p. 66, grifos da autora).

Em continuidade, falando sobre si e sobre o seu percurso acadêmico relata que se apaixonou pela faculdade, principalmente por entrar em uma área que "testa" a criatividade. “(...) dentro desta faculdade desde o início é mais prático, então a gente vai se envolvendo, não era aquilo que eu não gostava metodologicamente, daquelas repetições". Dos tempos de faculdade, relata ainda algumas experiências e alguns acontecimentos marcantes na sua trajetória. Dentre eles, destaca com maior ênfase o papel assumido por um professor, que não tornava o momento da aula significativo, pois entendia que os alunos seriam seus concorrentes futuramente no mercado de trabalho. "Naquela oportunidade ainda podia, não sei se tinha dedicação exclusiva naquela época, mas ele praticava, pra dizer que eu era concorrente. Não que eu tivesse feito um ótimo trabalho, mas o fato é de podar quem estava querendo crescer” (p. 5). Revela: “(...) 
aquilo me chocou muito" (p. 5). Então foi a primeira vez que a professora P começou a refletir sobre a posição do professor e sobre tornar-se professora - “(...) até então eu não tinha pensado em ser professora" (p. 5).

No momento em que dialogamos sobre as experiências anteriores ao seu ingresso na docência, fala sobre outros movimentos da sua vida, em destaque, fala sobre o seu ingresso e a sua experiência na Prefeitura Municipal de Santa Maria, em 1997. Aqui consegue atuar em uma área mais prática, participando, inclusive, da equipe de estruturação do Plano Diretor de Desenvolvimento Urbano Ambiental da cidade ${ }^{9}$ : “(...) entro numa Secretaria de Planejamento onde eu consigo atuar mais nas estratégias, na elaboração do Plano Diretor, que eu sempre sonhei, desde a graduação" (p. 8). E com isso, a partir desse trabalho de construção com foco numa visão mais participativa e no desenvolvimento sustentável, com a proposta “cidade, cidadão, cidadania” (p. 8), a professora $\mathrm{P}$ acaba sendo reconhecida na cidade e sendo convidada para dar aula na Universidade Regional Integrada do Alto Uruguai e das Missões (URI) - Santiago.

O início da docência quase sempre se constitui como um período de muitos desafios, para a professora $\mathrm{P}$ não foi diferente. Inicialmente ela fez algumas reflexões sobre a importância da docência e sobre o papel do professor, pois tinha claro na memória o que não queria ser, em função da experiência vivida na graduação com um professor. Reconhece que a sua empatia e a sua necessidade de saber "os porquês" das coisas para "(...) entender, aprender e transformar em conhecimento" (p. 9), facilitaram a sua relação com os alunos e o modo de organizar a sua prática. "Então foi nessa lógica, como eu gostava de aprender e não memorizar, eu era horrível para memorizar, eu tentava organizar o que eu fosse ensinar dessa forma. Tentando preparar o aluno para a transformação, mas me transformando junto com ele" (p. 9). Palavras que nos conduzem ao que escreve Freire (1996, p. 23), quando reflete que o processo de ensinar vai além de transferir conhecimento, implica construção, compreensão e intervenção no mundo, de todos os envolvidos; implica criar possibilidades de produção e construção e compreender que "Quem ensina aprende ao ensinar e quem aprende ensina ao aprender".

Além disso, reflete sobre a importância de reconhecer cada aluno no seu contexto e na sua cultura e sobre o significado da avaliação no processo formativo dos alunos. Esta

9 Consiste no instrumento básico da política de desenvolvimento sustentável urbano e rural da cidade. Informações disponíveis em: http://iplan.santamaria.rs.gov.br/site/home/pagina/id/148 Acesso em: 19 abr. 2018. 
última também se constitui como uma inquietação que vem da formação: “(...) a pior coisa pra mim era receber uma avaliação sem apontamentos, eu não sabia o que que era para melhorar (p. 9). Neste sentido, incorpora essas preocupações e constitui-se, ao longo do seu percurso, como uma professora extremamente preocupada e responsável por uma avaliação comprometida, qualitativa e ética.

Com o ingresso na ULBRA, em 2005, surgem novos desafios. Dentre eles, o desafio de reestruturar a linha de urbanismo ${ }^{10}$, dentro do Curso de Arquitetura e Urbanismo da instituição. "Então eu reestruturo essa linha numa visão muito mais prática do que conteudista" (p. 12), principalmente em função da sua experiência com a construção do Plano Diretor da cidade - trocas que também foram fundamentando o seu papel como professora. "Dentro da ULBRA a dificuldade maior era isso, de como é que se estruturava? Por que que não se reavaliava as coisas? Como é que eu, sozinha, poderia fazer isso? Não tinha que ser uma equipe?" Nesse percurso começa a defender que outros professores da linha participem do processo de reestruturação, pois reconhece a importância da construção de um espaço compartilhado e dialógico de discussão.

Então o início foi assim, é uma vontade de acertar muito grande, não posso dizer que acertei tudo né, mas faz parte, é um processo. Engraçado que esse novo diretor sempre me pergunta: e daí, tu deu a tua melhor aula? Acho que não né, porque acho que sempre posso melhorar. Nunca considero a aula excelente, porque acho que a gente sempre tem que buscar mais. Então essa busca sempre me motiva né. (p. 13).

A professora arquiteta revela que não teve grandes dificuldades no seu percurso de construção docente (construção permanente como ela mesma menciona), destacando a experiência profissional como um saber importante para a sua atuação no Ensino Superior. “(...) realmente o que me ajudou nesse crescimento como professor foi a minha prática profissional, como Arquiteta dentro de profissional liberal e depois como agente público dentro de uma Prefeitura” (p.16). Portanto, “(...) tudo o que eu levava para o

10 A linha de urbanismo, conforme a professora P, envolve as disciplinas de "Infraestrutura Urbana", Projeto Urbano 1, Projeto Urbano 2 e Projeto Urbano 3. 
aluno, eu já dizia onde e como poderia ser aplicado" (p. 16). Já trazia uma experiência vivida na prática com seus sucessos, problemas e conflitos. Nesse processo, acabou compreendendo que os alunos ficavam mais interessados e participativos, “(...) eles percebiam que não era algo utópico e que aquilo realmente faria parte da vivência deles enquanto profissionais" (p. 16).

Outro aspecto importante que aparece de forma intensa ao logo dos seus relatos, é a dedicação que tem com os seus alunos. Dedicação que está traduzida não só nas suas palavras, mas também nas suas ações e no seu modo de ser.

Uma coisa é o contexto geral da disciplina e outra é o particular do aluno. Então no particular do aluno eu vou de grupo em grupo, ou quando é trabalho individual, aluno por aluno. Percebo que eles têm a necessidade de falar, e se eles têm essa necessidade a gente tem que ouvir. Então aí eu saio meia noite da ULBRA, normalmente eu sou a última a fechar a porta, os guardas nem trancam, antes eles trancavam e agora eles nem trancam, eles dizem: não, a professora $P$ não saiu ainda (p. 17).

E acrescenta, “(...) falo isso, porque eu acho importante entender que a educação não está certa, tá faltando esse momento" (p. 16), de construção de um olhar atento, acolhedor e individual, que o professor precisa ter com os alunos mesmo atuando no Ensino Superior. Um olhar que nos leva a perceber que ser professor também envolve a construção de conhecimentos subjetivos - saber sentir, saber ouvir, saber se colocar no lugar do outro, pois as atitudes são tão importantes quanto o conhecimento (IMBERNÓN, 2011). "E o professor pra mim é isso, é saber sobre cada um e suas dificuldades" (p. 17).

Nesta história de conquistas, fala sobre a sua constante busca pelo conhecimento: "O doutorado de novo é aquela questão de querer melhorar um processo dentro da formação. A gente fala tanto que o professor precisa fazer formação continuada, então é exatamente isso, eu sou um processo em continuação (risos)" (p. 24, grifos meus). Narrativas que nos conduzem ao que escreve Gadotti (2003), quando menciona que para educar não basta ser reflexivo, é preciso dar sentido à reflexão e fazer da profissão um projeto de vida de continuar aprendendo. Neste contexto, como não ser atravessada pelas palavras da professora? Como não buscar inspiração para a nossa própria construção docente? Sobre isso, buscamos amparo teórico em Delory-Momberger (2008, p. 62, 
grifos da autora) quando diz que "A narrativa do outro é assim um dos lugares onde experimentamos nossa própria construção biográfica"; um dos lugares onde ampliamos horizontes e “(...) nos produzimos como sujeito de nossa biografia”.

O doutorado é “um despertar para esse novo conhecimento" (p. 25), é uma busca para tentar "entender um pouco mais das coisas que eu não conheço" (p. 25) e com isso "ver se eu consigo realizar alguma ação benéfica" (p. 25). É tentar ampliar os horizontes, buscar novos conhecimentos e "saber sintetizar isso numa prática real tua, no teu tempo, na tua hora, no teu momento, na tua circunstância de vida" (p. 25). Por que geografia? "Porque é complementar na parte de urbano, que realmente tem esse outro olhar, mas não é só geografia, eu queria depois fazer direito, eu queria fazer... Então a gente vai, é uma busca" (p. 25). Nesta trajetória, o doutorado é uma possibilidade de (auto)formação e intervenção social, na busca permanente de (auto)conhecimento. Assim, "Sair do plano ideal para a prática, não é abandonar o sonho para agir, mas agir em função dele, agir em função de um projeto de vida e de escola, de cidade, de mundo possível, de planeta... um projeto de esperança" (GADOTTI, 2003, p. 74).

A professora arquiteta busca nos seus percursos e nas relações familiares, valores para a construção de sua subjetividade e para a sua própria construção como docente. Com a mãe aprendeu a ser paciente e a buscar incessantemente a autonomia como mulher, também "amar a família e a pátria (Brasil)" (p. 1). Com o pai aprendeu a ter garra, persistência, coragem para enfrentar os problemas e o amor pela vida. "O amor pela vida de diferentes formas - pelas relações interpessoais, pela educação, pela escrita, pelos livros e pela natureza" (p. 1). Um amor que está registrado no seu modo de ser - no olhar, no tom da voz e na maneira encantadora de falar sobre a docência e sobre a educação.

A minha vontade era ensinar os meus alunos caminhando na cidade, só caminhando, percorrendo, e em cada momento uma coisa nova acontecendo e buscando as relações do conteúdo com aquele contexto que tu tá realizando, mas claro que hoje em dia a gente não tem como fazer isso ainda né. Mas era a minha vontade (p. 27).

A invenção de si representa uma possibilidade de fazer história, não apenas a história de uma bacharela que se tornou professora, mas de fazer história nos diferentes espaços que habita, nas relações que constrói e nos sonhos que acredita. Fazer história porque reconhece o potencial humano, as práticas solidárias, o processo permanente de 
inacabamento e a esperança como caminho para a transformação da educação. Como nos lembra Freire (2018, p. 15), a esperança é um imperativo existencial e histórico, mas é preciso integrar à esperança a consciência e a ação crítica, pois sozinha não ganha a luta e sem ela a luta fraqueja. "Enquanto necessidade ontológica a esperança precisa da prática para tornar-se concretude histórica. É por isso que não há esperança na pura espera”. Para a professora arquiteta:

(...) a esperança sempre fortalece esse sentimento de mudança, mas a mudança não acontece de uma hora pra outra, ela está acontecendo, é muito lenta. Não podemos é desistir né e tem muitas pessoas desistindo, só que tem muitos que estão tentando fazer a transformação. E tem muitos indecisos e se os indecisos vierem para o nosso lado, a gente ganha (risos). (p. 28, grifos meus).

Cabe aqui trazer o que escreve Josso (2007, p. 435) quando aborda a polissemia das representações no processo de invenção de si, "nossos fragmentos de memória individual e coletiva" se transformam em inspiração para que o nosso imaginário, mediante um olhar retrospectivo sobre nós mesmos, possa "inventar essa indispensável continuidade entre o presente e o futuro". A narrações centradas na formação ao longo da vida, segundo Josso (2007), revelam múltiplas formas e sentidos de "existencialidade singular-plural, criativa e inventiva do pensar, do agir e do viver junto" (p. 414). Esse trabalho de reflexão possibilitado pelas narrativas de formação, esse processo de pensar sobre si, de sensibilizar-se, permite algumas mudanças sociais e culturais nas vidas singulares, bem como mudanças que se relacionam com a evolução dos contextos profissionais e sociais dos sujeitos. Deste modo, a professora arquiteta não elabora apenas um discurso sobre si, mas constrói um projeto de si, de existência e de futuro.

\section{CONSIDERAÇÕES FINAIS}

A partir do desenvolvimento da pesquisa, foi possível compreender que a composição das tramas dessa professora revelou que a construção docência não tem uma definição exata, sendo construída nos percursos de vida, nos modos de escritas de si e no entrelaçamento com outras tramas, outras histórias, outras memórias. Tramas que revelaram que a docência acontece em um processo permanente de (auto)formação e 
(auto)conhecimento.

A docência como atividade profissional não aparece na trajetória da professora como algo planejado, como um desejo de infância ou um sonho de adolescência, mas como algo que foi sendo construído nos seus próprios percursos. A opção pela docência foi sendo alinhavada por representações pré-concebidas no meio familiar, no processo de escolarização e no percurso acadêmico. Escolhas que foram impulsionadas pelas marcas deixadas por alguns professores e pela influência de pessoas significativas.

As narrativas de vida da professora arquiteta revelaram ainda a construção de sentidos singulares que definem o ser professor - consciência de inacabamento, que apareceu em diferentes momentos da trajetória quando a professora reconhece que para ser professor é preciso estar disposto a buscar novos conhecimentos, estar em constante atualização e em permanente busca; (auto)formação permanente, que ficou definida no relato sobre a importância da formação pedagógica e de refletir constantemente, individual e coletivamente, sobre a prática, sobre as aulas e sobre o processo de avaliação; autoconhecimento, quando surgiu a reflexão sobre a importância do professor conhecer a si mesmo para melhor compreender o outro e suas ações; compartilhamento de experiências, com diferentes pessoas, contextos e práticas; movimentos, que definiram o professor como alguém que precisa incentivar o pensamento crítico, a formação humana e a busca por uma sociedade melhor e mais justa. O professor como alguém que precisa construir elos e mostrar que tudo no mundo está conectado - pessoas, contextos e sociedade; transformações, de pensamentos, conhecimentos, pessoas e do próprio sistema de ensino; e a busca por diferentes sonhos, dentre eles o sonho de ser educador e não só professor.

A pesquisa aponta para algumas especificidades e marca aspectos diferenciais no processo formativo e na construção da docência da professora arquiteta envolvida no estudo. Alguém que, diante da complexidade da educação, "desenha" uma engrenagem para definir o professor, para mostrar que tudo no mundo está conectado e que, pelo "movimento" da engrenagem, nós - professores, alunos e sociedade - podemos fazer diferente e participar de um processo mais amplo de transformação da educação. Professora arquiteta que acredita nas potencialidades do ser humano e na esperança como caminho para transformar a educação e compreende a docência como um processo permanente de buscas e desafios 


\section{REFERÊNCIAS}

ABRAHÃO, Maria Helena Menna Barreto. As narrativas de si ressignificadas pelo emprego do método autobiográfico. In: ABRAHÃO, M. H. M. B.; SOUZA, E. C. (Orgs.). Tempos, narrativas e ficções: a invenção de si. Porto Alegre: EDIPUCRS, 2006, p. 149-170.

ABRAHÃO, Maria Helena Menna Barreto. Pesquisa (auto)biográfica - tempo, memória e narrativas. In: ABRAHÃO, M. H. M. B. (Org.). A aventura (auto)biográfica: teoria e empiria. Porto Alegre: EDIPUCRS, 2004, p. 201-224.

BAUER, Martin W. GASKELL, George. Pesquisa qualitativa com texto, imagem e som: um manual prático. 9. ed. Petrópolis, RJ: Vozes, 2011.

BOLÍVAR, Antonio. A expressividade epistêmico-metodológica da pesquisa (Auto)Biográfica. In: ABRAHÃO, M. H. et al (Org.). Pesquisa (auto)biográfica, fontes e questões. 1 ed. Curitiba, PR: CRV, 2014, p. 113-127.

BOLÍVAR, Antonio; DOMINGO, Jesús. La investigación biográfica y narrativa en Iberoamérica: Campos de desarrollo y estado actual. In: Forum: qualitative social research. v. 7, n. 4, 2006, p. 1-43. Disponível em: < http://www.qualitativeresearch.net/index.php/fqs/article/view/161/358>. Acesso em: 03 jun. 2016.

BOLÍVAR, Antonio; DOMINGO, Jesús; FERNÁNDEZ, Manuel. La investigación biográfico-narrativa em educación: enfoque e metodologia. Madrid: La Muralla, S. A., 2001.

CUSATI, Iracema; SANTOS, Neide Elisa Porte dos Santos; CUSATI, Raphael Campos. Metodologia qualitativa nas pesquisas em educação: ensaio a partir dos estudos sobre Formação e Desenvolvimento Profissional Docente. Conjecturas, v. 21, n. 7, p. 335-351, 2021. Disponível em:

https://conjecturas.org/index.php/edicoes/article/view/423 Acesso em: 20 dez. 2021.

DELORY-MOMBERGER, Christine. Biografia e educação: figuras do indivíduoprojeto. Tradução de Maria da Conceição Passegi, João Gomes da Silva Neto, Luis Passegi. - Natal, RN: EDUFRN, São Paulo: Paulus, 2008. 
FREIRE, Paulo. Pedagogia do Oprimido. $17^{\circ}$ edição. Rio de Janeiro: Paz e Terra, 1987. 110p.

FREIRE, Paulo. Pedagogia da Autonomia: saberes necessários à prática educativa. 37. ed. São Paulo, Paz e Terra, 1996.

FREIRE, Paulo. Pedagogia da Esperança: um reencontro com a pedagogia do oprimido. 24. ed. Rio de Janeiro: Paz e Terra, 2018.

FISCHER, Beatriz T. Daudt. Introdução: De enguias e outras metáforas. In: FISCHER, Beatriz T. Daudt (Org.). Tempos de escola: memórias. Volume II. São Leopoldo: Oikos, Brasília: Liber Livro, 2011, p. 17-24.

GADOTTI, Moacir. Boniteza de um sonho: ensinar-e-aprender com sentido. Novo Hamburgo: Feevale, 2003, 80p.

IMBERNÓN, Francisco. Formação docente e profissional: formar-se para a mudança e a incerteza. São Paulo: Cortez, 9. ed., 2011.

JOSSO, Marie-Christine. A transformação de si a partir da narração de histórias de vida. Educação, Porto Alegre, v. 30, n. 3, p.413-438, set./dez., 2007.

JOSSO, Marie-Christine. Experiências de vida e formação. Natal: EDUFRN;

São Paulo: Paulus, 2010.

JOVCHELOVITCH, Sandra; BAUER, Martin W. Entrevista Narrativa. In: BAUER, Martin W. GASKELL, George. Pesquisa qualitativa com texto, imagem e som: um manual prático. 9. ed. Petrópolis, RJ: Vozes, p. 90-113, 2011.

MORAES, Letícia Baldasso; MARINHO, Alcyane. Brizoletas: um passeio pela memória, patrimônio cultural e educação. Educação. Santa Maria, v. 42, n. 31, p. 615628, set./dez. 2017.

QUADROS, Claudemir de. Marcas do tempo: imagens e memórias das Brizoletas. Santa Maria: Unifra, 2005. 120p. 